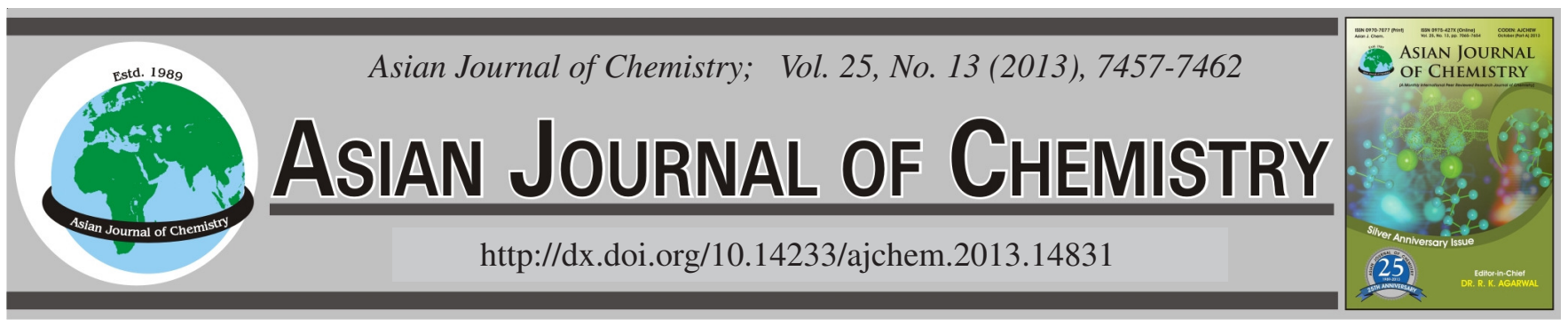

\title{
Evaluation of Antioxidant and Cytotoxicity Studies of Clerodendrum inerme
}

\author{
Shakeel Ahmad Khan ${ }^{1}$, Nasir Rasool ${ }^{1, *}$, Muhammad Riaz ${ }^{1}$, Raziya Nadeem², Umer Rashid",*, \\ Komal Rizwan ${ }^{1}$, Muhammad Zubair $^{1}$, Iftikhar Hussain BukHari ${ }^{1}$ and Tahsin Gulzar ${ }^{4}$
}

\begin{abstract}
${ }^{1}$ Department of Chemistry Government College University, Faisalabad-38000, Pakistan
${ }^{2}$ Department of Chemistry and Biochemistry, University of Agriculture, Faisalabad-38040, Pakistan

${ }^{3}$ Institute of Advanced Technology, Universiti Putra Malaysia, 43400 UPM Serdang, Selangor, Malaysia

${ }^{4}$ Department of Applied Chemistry, Government College University, Faisalabad-38000, Pakistan
\end{abstract}

*Corresponding authors: Fax: +92 41 9201032; Tel: +92 332 7491790; E-mail: nasirhej@yahoo.co.uk (Nasir Rasool) Fax: +60 3894670041; Tel: +60 389467393; E-mail: umer.rashid@yahoo.com (Umer Rashid)

\begin{abstract}
Clerodendrum inerme has been identified as a source of natural antioxidants. The aim of this work was to check the antioxidant activity of $C$. inerme stem by measuring total phenolic contents, total flavonoid contents, DPPH free radical scavenging assay, reducing power and percentage inhibition of linoleic acid peroxidation. Total phenolic contents and total flavonoid contents values were found to be in the range $(0.89-1.89 \mathrm{mg} / 100 \mathrm{~g} \mathrm{GAE})$ and $(3.18-5.68 \mathrm{mg} / 100 \mathrm{~g} \mathrm{CE})$ respectively. The $\mathrm{IC}_{50}$ and percentage inhibition of linoleic acid peroxidation values of $C$. inerme extracts ranged from $(24.1-81 \mu \mathrm{g} / \mathrm{mL})$ and $(41-72 \%)$ respectively. Peroxide value, free fatty acid and para-anisidine values were also studied by stabilizing the canola oil as oxidation substrate. The results showed that methanol extract of $C$. inerme stem showed better antioxidant activity. The cytotoxicity studies carried out by haemolytic activity of plant extracts against the human erythrocytes (RBCs) in vitro was studied and found to be in the range (1.41-5.75\%) in different extracts.
\end{abstract}

Key Words: Clerodendrum inerme, Antioxidants, Phytochemicals, Cytotoxicity, Stabilization.

\section{INTRODUCTION}

Nature has blessed aerobic organisms with an inner defense system that resists against oxidative damage due to reactive oxygen species. However, supplementing the natural defense mechanism with dietary antioxidants might offer better protection against the risk of certain cancers, inflammation and other degenerative diseases ${ }^{1}$. The addition of synthetic antioxidants such as butylated hydroxyl anisole and butylated hydroxytoluene in lipid containing foods is often discouraged due to their safety and perceived carcinogenicity. On the other hand, the use of plant based antioxidant compounds in foods and preventive medicine are gaining a great deal of interest because of their potential health benefits ${ }^{2-5}$. It is well accepted that plants are the richest source of antioxidants.

Numerous studies on $C$. inerme have been reported in different traditional medical systems, e.g. in Thai traditional medicine, it is used to treat skin diseases. The tincture or decoction from these leaves is used in the traditional Indian medicine for the treatment of remittent and intermittent fevers, while the juice of leaves and roots is used as an alternative sources to treat scrofulous and venereal diseases. Antiinflammatory, antifungal, antimicrobial and several other useful properties of $C$. inerme have also been reported ${ }^{6}$. Genus Clerodendrum L. known as garden quinine on account of its intense bitter taste and used as a substitute for quinine ${ }^{7}$. Flavonoids and phenolic compounds are widely distributed in plants which have been reported to exert multiple biological effects, including antioxidant, free radical scavenging abilities, antiinflammetry and anticarcinoginic, etc. Different parts of the $C$. inerme plant products are used in the Ayurvedic medicine for the treatment of rheumatism, skin disease, veneral infections, beri-beri and tumours ${ }^{8}$. These plant extracts are used in Asian countries for various diseases where free radicals are thought to be involved. The methods namely free radical scavenging activity by DPPH test, hydroxyl radical scavenging activity and lipid peroxidation by thiobarbituric acid assay were employed to asses the antioxidant activities ${ }^{9}$. In Indian tribal medicine, leaves of $C$. inerme are used for treating fever, cough, skin rashes and boils and are used in conjunction with other plant leaves. They are also used to treat umbilical cord infection and for cleaning the uterus in local medicine ${ }^{10}$. It is reported that tribals use $C$. inerme as an antidote of poisoning from fish, crabs and toads. Juice of leaves is used for the treatment of skin diseases such as polities, itches, leprosy and scabies, scrofulous. It is an important medicinal plant reported to be 
used for the treatment of elephantiasis, asthma and topical burns $^{7}$. The insecticidal activity results proved that $C$. inerme leaf powder and petroleum ether extracts inhibited the growth and development of Aedes aegypti, Culex quinquefasciatus and Culex pipiens larvae. The aim of the present investigation was to evaluate the in vitro antioxidant, phytochemical study of the $C$. inerme stem and also involve the determination of antioxidant activity using canola oil as oxidation substrate.

\section{EXPERIMENTAL}

The stem of the plant $C$. inerme was collected from the local areas of Faisalabad, Pakistan in June 2011. The specimen was further identified and authenticated from Taxonomist, Department of Botany and University of Agriculture Faisalabad, Pakistan. All chemicals used for this work were purchased from Merck (Darmstadt, Germany) and Sigma chemicals USA. All other reagents used in this study were also of analytical grade.

Preparation of extracts: The dried sample was grinded (80 mesh size) by using a commercial blender (TSK-949, West point, France). The stem of $C$. inerme $(200 \mathrm{~g})$ in powder form was soaked in petroleum ether for one week. The extract was separated from residue by filtering through Whatman No.1 filter paper. Further extracts were made by dipping remaining residue in different polarity based solvent systems such as petroleum ether:chloroform (1:1), ethyl acetate, ethyl acetate: chloroform (1:1), chloroform, ethanol and methanol. All the extracts were separated from residues using Whatman filter paper No.1 and concentrated and freed of solvent under reduced pressure at $50{ }^{\circ} \mathrm{C}$, using a rotary evaporator. The extracts were weighed to calculate the yield and stored until used for analysis. The crude extracts were weighed to calculate the yield and stored in a refrigerator $\left(4^{\circ} \mathrm{C}\right)$, until used for further work ${ }^{11,12}$.

Phytochemical analysis: Chemical tests were carried out on the petroleum ether, petroleum ether:chloroform (1:1), ethyl acetate, ethyl acetate:chloroform (1:1), chloroform, ethanol and methanol extracts of $C$. inerme stem using standard procedures to identify the constituents as described ${ }^{13,14}$ with some modifications.

Total phenolic contents and total flavonoid contents: Amount of total phenolic contents was estimated using FolinCiocalteu reagent following procedure as described by Chaovanalikit and Wrolstad ${ }^{15}$. Total flavonoid contents were estimated spectrophotometrically following the procedure described by Dewanto et al. ${ }^{16}$.

\section{Evaluation of antioxidant activity of plant extracts}

DPPH Free radical scavenging assay: The 1,1'-diphenyl2-picrylhydrazyl radical (DPPH) assay was performed as described by previous workers ${ }^{12,17}$. The $\mathrm{IC}_{50}$ values were calculated from the plot of percentage scavenging against concentration of different extracts used. Three replicates were recorded for each sample.

Antioxidant activity in linoleic acid system: In linoleic acid system antioxidant activity of plant extracts was determined by following the earlier method described ${ }^{18} .5 \mathrm{mg}$ of each extract was added to a $0.13 \mathrm{~mL}$ of solution mixture of linoleic acid. Then $10 \mathrm{~mL}$ of $99.8 \%$ ethanol and $10 \mathrm{~mL}$ of
$0.2 \mathrm{M}$ sodium phosphate buffer $(\mathrm{pH}=7.0)$ was added to the reaction mixture and diluted up to $25 \mathrm{~mL}$ with distilled water. The solution was incubated at $40^{\circ} \mathrm{C}$ for $175 \mathrm{~h}$. Afterwards the degree of oxidation was measured following thiocyanate method. Took $10 \mathrm{~mL}$ of ethanol (75\%), $0.2 \mathrm{~mL}$ of an aqueous solution of ammonium thiocyanate (30\%), $0.2 \mathrm{~mL}$ of sample solution and $0.2 \mathrm{~mL}$ of ferrous chloride solution $(20 \mathrm{mM}$ in $3.5 \% \mathrm{HCl}$ ). Stirred well for $3 \mathrm{~min}$ and absorption was determined at $500 \mathrm{~nm}$ as peroxides content. A control was performed with linoleic acid but without extracts. Butylated hydroxyl toluene was taken as positive control. The maximum peroxidation level observed as $175 \mathrm{~h}$ in the sample that contained no antioxidant component was used as test point. Percentage inhibition of linoleic acid peroxidation was calculated to exhibit antioxidant activity.

$\%$ inhibition of peroxidation $=100-[($ Abs. increase of sample at $175 \mathrm{~h} / \mathrm{Abs}$. increase of control at $175 \mathrm{~h}) \times 100$ ]

Reducing power: The reducing power of the plant extracts was determined according to the method described ${ }^{19}$.

Antioxidant activity of $C$. inerme stem extracts using canola oil as oxidation substrate: Canola oil was used as an oxidation substrate. The antioxidant activity of plant stem was determined by using accelerated aging of refined, bleached and deodorized (RBD) canola oil. The crude concentrated different extracts of the plant material were separately added to preheated $\left(50{ }^{\circ} \mathrm{C}\right)$ refined, bleached and deodorized canola oil at plant extract concentration of $500 \mathrm{ppm}$. The oil samples were stirred for $0.5 \mathrm{~h}$ at $50^{\circ} \mathrm{C}$ for uniform dispersion. Synthetic antioxidant was used at its legal limit of $200 \mathrm{ppm}$ to compare the efficiency of extracts. Stabilized and control oil samples $(100 \mathrm{~mL})$ were placed in dark brown airtight glass bottles with narrow necks and subjected to accelerated storage in an electric oven at $60{ }^{\circ} \mathrm{C}$ for 28 days. A control (without the addition of any antioxidant extract) sample was also prepared under the same set of analytical conditions as reported method ${ }^{11,12}$. During storage, the oil samples were taken out for analysis after every 7 days. The oxidative deterioration levels of the oils were assessed by the determinations of peroxide value, free fatty acid (FFA \%) contents and para-anisidine values ${ }^{12}$.

Peroxide value and free fatty acid (FFA \%) contents: The peroxide value and free fatty acid (FFA \%) contents of stabilized and the control canola oil samples were measured

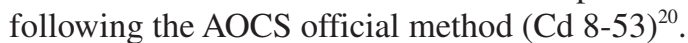

p-Anisidine value: The $p$-anisidine value is a measure of $\alpha$ - and $\beta$ unsaturated aldehyde (Principally 2-alkenals and 2, 4 -dienals) present in the sample. They are common secondary oxidation products. They react with $p$-anisidine to produce colour compounds that can be determined spectrophotometerically (IUPAC method II. D. $26^{21}$.

Cytotoxicity studies: The cytotoxicity was determined by using the reported method ${ }^{22,23} .3 \mathrm{~mL}$ of freshly obtained heparinized human blood was gently mixed, poured into a sterile $15 \mathrm{~mL}$ falcon tube and centrifuged for $5 \mathrm{~min}$ at $850 \times \mathrm{g}$. The supernatant was poured off and viscous pellet washed three additional times with $5 \mathrm{~mL}$ of chilled $\left(4{ }^{\circ} \mathrm{C}\right)$ sterile isotonic phosphate-buffered saline solution, adjusted to $\mathrm{pH}$ 7.4 , to stabilize the $\mathrm{pH}$ mix it almost for $0.5 \mathrm{~h}$ at room temperature $\left(25-30{ }^{\circ} \mathrm{C}\right)$. The washed cells were suspended in the 20 $\mathrm{mL}$ chilled, saline phosphate buffer saline buffer. Erythrocytes 
\% YIELD OF EXTRACT, TOTAL PHENOLIC CONTENTS, TOTAL FLAVONOID CONTENTS AND ANTIOXIDANT ASSAYS OF $C$. inerme EXTRACTS

\begin{tabular}{|c|c|c|c|c|c|}
\hline Samples & $\begin{array}{c}\% \text { Yield of } \\
\text { extract }(\mathrm{g} / 100 \mathrm{~g})\end{array}$ & $\begin{array}{c}\text { TPC (mg/100 g) } \\
\text { as GAE }\end{array}$ & $\begin{array}{l}\text { TFC (mg/100 g) } \\
\text { as CE }\end{array}$ & $\begin{array}{c}\mathrm{DPPH} \mathrm{IC}_{50} \\
(\mu \mathrm{g} / \mathrm{mL})\end{array}$ & $\begin{array}{c}\% \text { Inhibition of linoleic } \\
\text { acid oxidation }\end{array}$ \\
\hline Petroleum ether & $10.41 \pm 0.06$ & $1.59 \pm 0.02$ & $5.09 \pm 0.05$ & $34.1 \pm 0.49$ & $59.7 \pm 0.47$ \\
\hline Petroleum ether: Chloroform (1:1) & $9.50 \pm 0.07$ & $1.30 \pm 0.01$ & $4.41 \pm 0.04$ & $46.4 \pm 0.37$ & $68.4 \pm 0.49$ \\
\hline Ethyl acetate & $8.64 \pm 0.06$ & $1.06 \pm 0.03$ & $3.80 \pm 0.03$ & $46 \pm 0.70$ & $72.0 \pm 0.76$ \\
\hline Ethyl acetate: Chloroform(1:1) & $7.99 \pm 0.08$ & $1.03 \pm 0.02$ & $3.31 \pm 0.02$ & $54.9 \pm 0.58$ & $56.0 \pm 0.40$ \\
\hline Chloroform & $6.96 \pm 0.04$ & $0.89 \pm 0.04$ & $3.18 \pm 0.04$ & $81.2 \pm 0.63$ & $61.5 \pm 0.75$ \\
\hline Ethanol & $8.53 \pm 0.05$ & $1.02 \pm 0.02$ & $3.50 \pm 0.05$ & $67.7 \pm 0.56$ & $41.0 \pm 0.30$ \\
\hline Methanol & $11.33 \pm 0.09$ & $1.89 \pm 0.02$ & $5.68 \pm 0.07$ & $24.1 \pm 0.41$ & $53.0 \pm 0.69$ \\
\hline BHT & - & - & - & $20.5 \pm 0.42$ & $81.0 \pm 0.75$ \\
\hline
\end{tabular}

were counted on haemocytometer. The blood cell suspension was maintained on wet ice and diluted with sterile, the cell count maintained at $7.068 \times 10^{8}$ cells per $\mathrm{mL}$ for each assay. $20 \mu \mathrm{L}$ of plant extract in five different solvent was taken in 2 $\mathrm{mL}$ eppendorf tubes. For each assay, $0.1 \%$ Triton X-100 was taken as a positive control, phosphate buffer saline was taken for each assay as a negative control, background. In each 2 $\mathrm{mL}$ eppendorf tube already contain $20 \mu \mathrm{L}$ samples and add $180 \mu \mathrm{L}$ diluted blood cell suspension and mixed it with the help of pipette tip. Tubes was incubated for $35 \mathrm{~min}$ at $37^{\circ} \mathrm{C}$. Immediately after incubation, the tubes was placed on ice for $5 \mathrm{~min}$ then centrifuged for $5 \mathrm{~min}$ at $1310 \times \mathrm{g}$. After centrifugation $100 \mu \mathrm{L}$ supernatant was taken from the tubes and diluted with $900 \mu \mathrm{L}$ chilled phosphate buffer saline. All tubes were maintained on wet ice after dilution. Than $200 \mu \mathrm{L}$ into 96 well plates and three replicate was taken in well plate which contain one positive control (100\% of blood lysis) and other negative control ( $0 \%$ of blood lysis). After this absorbance at $576 \mathrm{~nm}$ was taken at $\mu$ Quant micro plate reader.

Statistical analysis: Analysis was done in triplicate and data reported as mean \pm SD. Results of the present analysis were statistically analyzed applying student test at $95 \%$ confidence level.

\section{RESULTS AND DISCUSSION}

Phytochemical studies: Phytochemical components such as alkaloids, flavonoids, saponins, tannins and anthraquinones were analyzed in $C$. inerme. Phytochemical analysis revealed that important chemicals like alkaloids, flavonoids, tannins and saponins were present while anthraquinones were absent in the plant under study. Phytochemical analysis of Clerodendrum inerme showed that this plant has rich amount of alkaloids, flavonoids, tannins and saponins.

Percentage yield of extracts: The $\%$ yields of $C$. inerme extracts were found within the range of 6.96 to $11.33 \%$ for the solvents used (Table-1). The maximum yield obtained with methanol $(11.33 \%)$, while the minimum with chloroform $(6.96 \%)$. The percentage yield of different extracts of $C$. inerme in different solvents system decreased in the following order, methanol $(11.33)>$ petroleum ether $(10.41)>$ petroleum ether:chloroform $(9.50)>$ ethyl acetate $(8.64)>$ ethanol (8.53) > ethyl acetate:chloroform (7.99) > chloroform (6.96) $\%$, respectively. The results demonstrated a significant $(p<$ 0.05 ) difference in extract yields among the solvent system used. Anwar et al. ${ }^{24}$ studied the antioxidant activity of fennel seeds and reported higher yield with methanol extract $(12.11 \%)$. Our present analysis revealed somewhat lower extract yields of the investigated plant material. Due to the polar nature of natural antioxidants, the yield of components goes on an increase with increasing polarity of the solvent. Hence, methanol is usually employed for maximum extraction of antioxidant components from plants as compared to other organic solvents due to polarity and good solubility of many antioxidant components ${ }^{19}$.

Antioxidant studies: Antioxidants results of all the tests are documented in Table-1. Total phenolic contents obtained from extracts of different solvents, ranged from 0.89-1.89 mg/ $100 \mathrm{~g}$ GAE of dry plant extracts. The highest total phenolic contents $(1.89 \mathrm{mg} / 100 \mathrm{~g} \mathrm{GAE})$ were observed in methanol extract while lowest total phenolic contents value $(0.89 \mathrm{mg} /$ $100 \mathrm{~g}$ GAE) was observed in chloroform extract. The amount of total phenolic contents among different solvent systems of C. inerme decreased in the following order, methanol (1.89) > petroleum ether $(1.59)>$ petroleum ether:chloroform $(1.30)>$ ethyl acetate $(1.06)>$ ethyl acetate:chloroform $(1.03)>$ ethanol (1.02) > chloroform (0.89) GAE mg/100 g of dry plant extract. The total phenolic contents in the presently investigated methanol extract of stem of Clerodendrum inerme in percentage ( $8.36 \%$ of gallic acid equivalents) was higher than in methanolic extract of $C$. inerme leaves.

Total flavonoid contents obtained from plant extracts ranged from 3.18 to $5.68 \mathrm{mg} / 100 \mathrm{~g}$ catechin equivalent of dry extracts. Highest total flavonoid contents $(5.68 \mathrm{mg} / 100 \mathrm{~g})$ was observed in methanol while lowest total flavonoid contents $(3.18 \mathrm{mg} / 100 \mathrm{~g})$ was observed in chloroform extract. The degree of total flavonoid contents among different solvent systems of $C$. inerme decreased in the following order, methanol (5.68) $>$ petroleum ether (5.09) > petroleum ether:chloroform (4.41) > ethyl acetate (3.80) > ethanol (3.50) > ethyl acetate: chloroform (3.31) > chloroform $(3.18 \mathrm{mg} / 100 \mathrm{~g}) \mathrm{CE}$ of dry extracts respectively. Differences in the total flavonoid contents of extracts from plants might be attributed to the availability of different extractable components, chemical composition and nature of soil conditions. Among other parameters effectiveness of the extracting solvents to dissolve endogenous components ${ }^{25}$. As per literature review the determined flavonoid contents in methanol extract of plants results are some what comparable with our findings. The amounts were found in percentage as 
$0.13 \%$ of catechin equivalents of flavonoid contents. The amount of total flavonoid contents in the present study of methanolic extract in precentage is $25.13 \%$ of catechin equivalents.

The $\mathrm{IC}_{50}$ values ranged from $(24.1-81 \mu \mathrm{g} / \mathrm{mL})$. The lowest $\mathrm{IC}_{50}$ value $(24.1 \mu \mathrm{g} / \mathrm{mL})$ was exhibited by methanol extract and highest value $(81 \mu \mathrm{g} / \mathrm{mL})$ with chloroform extract. The $\mathrm{IC}_{50}$ values of $C$. inerme decreased in the following order, chloroform (81.2) > ethanol (67.7) > extract ethyl acetate: chloroform (54.9) > petroleum ether:chloroform (46.4) > ethyl acetate $(46)>$ petroleum ether $(34.1)>$ methanol $(24.1)>$ butylated hydroxytoluene (20.5) $\mu \mathrm{g} / \mathrm{mL}$. The results of the present analysis are comparable to some extent with the results of ${ }^{9}$. They determined the $\mathrm{IC}_{50}$ values of methanol $\left(\mathrm{IC}_{50} 19.20\right.$ $\mu \mathrm{g} / \mathrm{mL})$ and petroleum ether $\left(\mathrm{IC}_{50} 28.42 \mu \mathrm{g} / \mathrm{mL}\right.$ ) extract of the plant sources. It was concluded that in the present study, methanol extract and petroleum ether extract exhibited stronger free radical scavenging activity some what comparable to earlier reports ${ }^{9}$. The $\%$ inhibition of peroxidation in linoleic acid system ranged from 41 to $72 \%$. The ethyl acetate exhibited highest inhibition $(72.0 \%)$ and ethanol showed lowest inhibition $(41.0 \%)$. Percentage inhibitions of different extracts of $C$. inerme stem decreased in the following order, butylated hydroxytoluene $(81.0)>$ ethyl acetate $(72.0)>$ petroleum ether:chlorform (68.4) > chloroform $(61.5)>$ petroleum ether (59.7) > ethyl acetate:chlorform (56.0) > methanol (53.0) > ethanol (41.0). All extracts exhibited appreciable inhibition of peroxidation and were compared with butylated hydroxytoluene having inhibition of peroxidation $81.00 \%$. All extracts exhibited lower peroxidation as compared to butylated hydroxytoluene. They determined the $\%$ inhibition $(59.49 \%)$ of methanol extract of Clerodendrum phlomidis. Considerable inhibition of peroxidation of $C$. inerme extracts might be due to the presence of established antioxidants, such as xanthones, flavans, flavonols and di-antraquinones ${ }^{19}$.

All results of reducing potential of different extracts of of $C$. inerme stem documented in Table-2. The reducing power of the extracts increased in a concentration-dependent manner. Therefore reducing power evaluation might be taken as important parameter for the assessment of antioxidant activity

Antioxidant potential of $C$. inerme stem extracts for stabilization of canola oil: The peroxide value is commonly used to assess the magnitude of primary oxidation products (mainly the peroxides) in oils ${ }^{26}$. The relative increases in the peroxide values of the stabilized canola oil with different extracts and control without extracts is shown in Fig. 1. The increase in peroxide values of samples stabilized with different extracts of plant stem was significantly less than the control
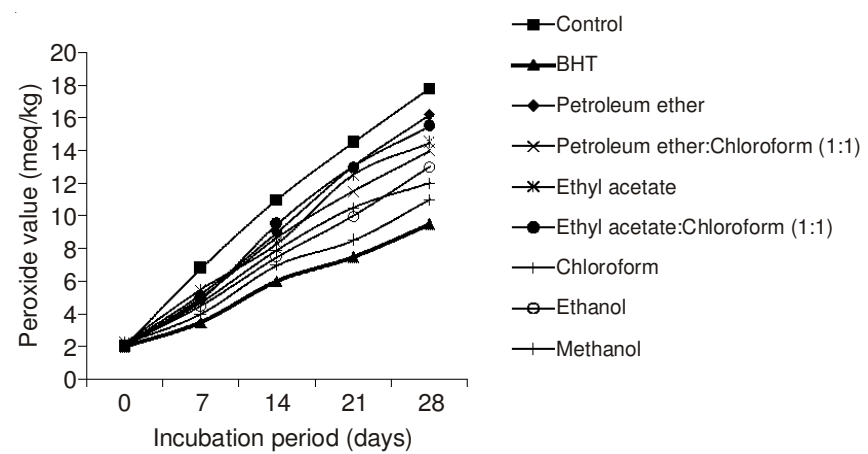

Fig. 1. Peroxide value $(\mathrm{meq} / \mathrm{kg})$ of canola oil stabilized with $C$. inerme stem extracts under accelerated storage

showing less degree of deterioration. Whereas the control sample showed higher value of peroxide values showing greater degree of oxidation. The methanol extracts of $C$. inerme stem showed low value of peroxide values (11), it might be due to the highest concentration of phenolics. As per literature review the ginger extracts at concentrations of $1600 \mathrm{ppm}$ and 2400 ppm greatly inhibited the rise in peroxide values the results are some what comparable with our findings ${ }^{27}$ and also the reported value of peroxide values in $100 \%$ methanol extract 17.20 with soybean oil is in agreement with the present analysis findings.

The measurement of free fatty acid contents of oil samples stabilized with different extracts of $C$. inerme stem was carried out. The relative increases in the free fatty acid of the stabilized and control canola oil are presented in Fig. 2. All the extracts were found to show a slow initially, followed by a gradual increase in free fatty acid contents. Methanolic extract showed the higher antioxidant activity in terms of free fatty acid as compared to the other extracts. The lower values of free fatty

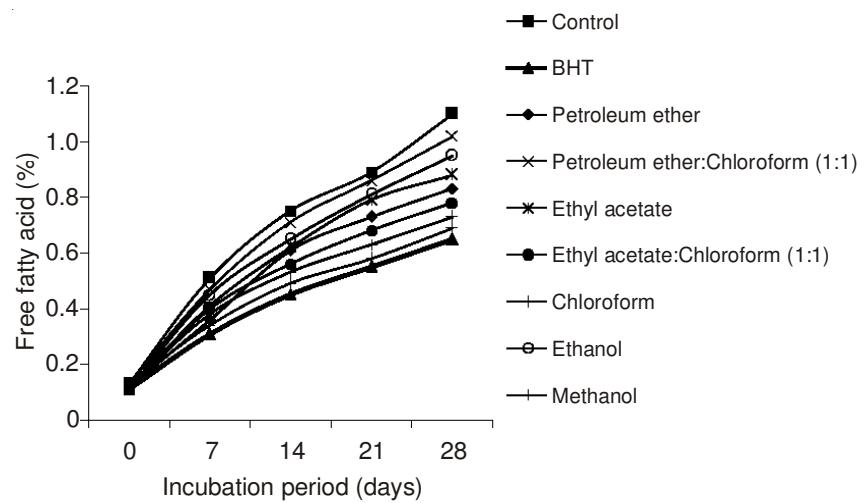

Fig. 2. Free fatty acid values of canola oil stabilized with $C$. inerme stem extracts under accelerated storage

TABLE-2

REDUCING POTENTIAL OF DIFFERENT EXTRACTS OF STEM OF C. inerme

\begin{tabular}{|c|c|c|c|c|}
\hline \multirow{2}{*}{ Samples } & \multicolumn{4}{|c|}{ Concentration of extracts $(\mathrm{mg} / \mathrm{mL})$} \\
\hline & 2.5 & 5.0 & 7.5 & 10.0 \\
\hline Petroleum ether & $0.38 \pm 0.003$ & $0.49 \pm 0.005$ & $0.58 \pm 0.004$ & $0.69 \pm 0.007$ \\
\hline Petroleum ether:Chloroform (1:1) & $0.28 \pm 0.002$ & $0.18 \pm 0.002$ & $0.21 \pm 0.004$ & $0.24 \pm 0.001$ \\
\hline Ethyl acetate & $0.57 \pm 0.005$ & $0.62 \pm 0.005$ & $0.68 \pm 0.004$ & $0.71 \pm 0.006$ \\
\hline Ethyl acetate:Chloroform $(1: 1)$ & $0.33 \pm 0.004$ & $0.48 \pm 0.004$ & $0.54 \pm 0.002$ & $0.56 \pm 0.004$ \\
\hline Chloroform & $0.37 \pm 0.002$ & $0.40 \pm 0.003$ & $0.43 \pm 0.003$ & $0.48 \pm 0.004$ \\
\hline Ethanol & $0.79 \pm 0.008$ & $0.86 \pm 0.005$ & $0.88 \pm 0.006$ & $0.93 \pm 0.008$ \\
\hline Methanol & $0.54 \pm 0.004$ & $0.58 \pm 0.004$ & $0.67 \pm 0.001$ & $0.70 \pm 0.008$ \\
\hline
\end{tabular}

Values (mean \pm SD) are the average of triplicate, analysed individually in triplicate, $(p<0.05)$. 
acid contents of stabilized oil sample than control indicated the effectiveness of $C$. inerme stem extracts as natural antioxidant in retarding the free fatty acid formation. The increase in free fatty acid contents of control canola oil (without extracts) indicated the formation of hydrolyzed and oxidized products during the storage period. As per literature survey the deterioration of oils the initial step is the formation of free fatty acid, which is susceptible to the attack of oxygen in the presence of light, resulting in the formation of many organic compounds and free fatty acid which are responsible for the development of rancidity in fatty food materials ${ }^{24}$.

The stabilized and control canola oil by different extracts of $C$. inerme is shown in Fig. 3. There is a relative increase in $p$-anisidine values of oil stabilized with extracts of $C$. inerme stem under accelerated condition (room temperature for 28 days). The control (without any extract) showed the highest $p$-anisidine value indicated a higher rate of oxidation. Methanolic extract of $C$. inerme shows lower $p$-anisidine value as compared to other extracts. para-Anisidine value is used to measure the secondary products of lipid oxidation. This method determined the amount of aldehyde (principally 2 alkenals and 2,4 dienals) in animal fat and vegetable oils. Aldehyde in oil and $p$-anisidine reagent reacts under acidic conditions. The para-anisidine value, which generally reflects the amount of aldehydic secondary oxidation products in oils ${ }^{28}$. The proposed reaction of $p$-anisidine with aldehyde formed a yellow product. The assessment of antioxidant activity of plant extracts using the measurement of $p$-anisidine value of oils is generally recognized $^{11}$.

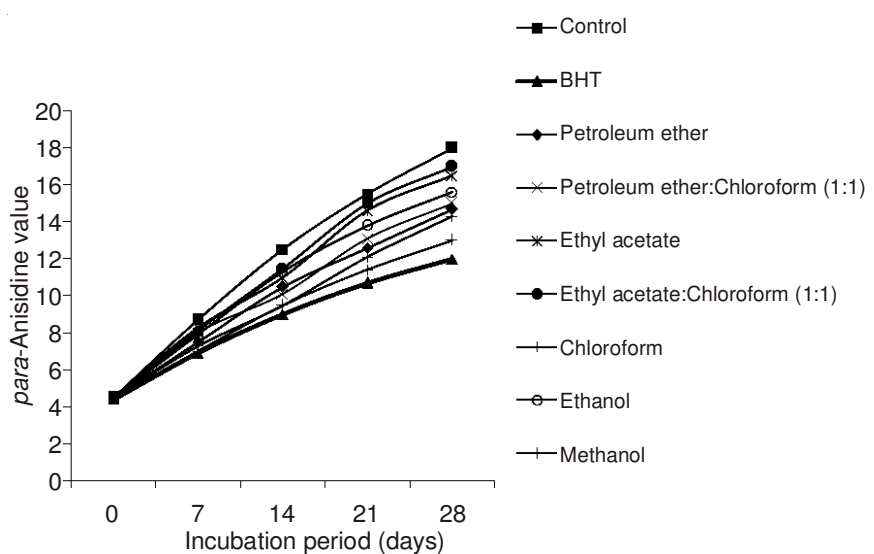

Fig. 3. $p$-Anisidine values of canola oil stabilized with $C$. inerme extracts under accelerated storage

From the results of different antioxidant assays and various oxidation parameters of canola oil stabilized with plant extracts, it is understandable that methanol extracts exhibited good antioxidant activity. However the antioxidant activity of the methanolic extract was found to be significantly higher than other solvent extracts. The antioxidant activity of extracts of $C$. inerme as exhibited in the present analysis might be attributed to the presence of significantly high amount of polyphenolics and other antioxidant substances as analyzed during the phytochemical and antioxidant assays in this study.

Cytotoxicity studies: The cytotoxicity of $C$. inerme stem extract was observed by haemolytic activity results showed by different extracts of $C$. inerme (petroleum ether, petroleum ether:chloroform (1:1), ethyl acetate, ethyl acetate:chloroform (1:1), chloroform, ethanol, methanol, phosphate Buffer saline and Triton $\times 100$ are 3.53, 2.31, 3.90, 1.41, 1.81, 5.75, 2.82, 0 and $99.06 \%$ respectively. The plant extracts showed minor cytotoxicity found to be less than $6 \%$. So it is concluded that the plant extracts are not cytotoxic. The plants extracts which are less cytotoxic might be used as herbal medicines ${ }^{29}$.

\section{Conclusion}

The results of the present study indicated that phenolic compounds are good scavengers of free radicals as demonstrated by a good relation of DPPH scavenging activity with total phenolic contents, while studying the different extracts of stem of $C$. inerme. Moreover, little correlation between total flavonoid contents and percentage inhibition has been observed and also the extracts derived from $C$. inerme stem were found to be quite effective towards suppressing the primary and secondary oxidation products in the tested canola oil. In the present study of $C$. inerme stem showed better antioxidant activity and sizeable amounts of total phenolic contents and total flavonoid contents. The results of the present study would help to learn the potency of crude extracts of stem of $C$. inerme as potential source of natural antioxidants and suggests that $C$. inerme stem might be explored as a viable source of potent antioxidants for the protection of vegetable oils from oxidation. However, further research is needed to identify individual components forming antioxidative system and develop their applications for food and pharmaceutical industries.

\section{REFERENCES}

1. T. Madhujith and F. Shahidi, Pharm. Biol., 46, 88 (2008).

2. E.M. Abdallah and A.E. Khalid, Int. J. Chem. Biochem. Sci., 1, 1 (2012).

3. A. Ghiselli, M. Serafini, F. Natella and C. Scaccini, Free Radic. Biol. Med., 29, 1106 (2000).

4. A.I. Hussain, F. Anwar, S. Tufail, H. Sherazi and R. Przybylski, Food Chem., 108, 986 (2008).

5. K. Rizwan, M. Zubair, N. Rasool, M. Riaz, M. Zia-Ul-Haq and D.V. Feo, Int. J. Mol. Sci., 13, 6440 (2012).

6. M.A. Farooqui, P.S. Chauhan, P. Krishnamoorthy and J. Shaik, Digest J. Nanomater. Biostruct., 5, 43 (2010).

7. G. Garima, J. Curr. Res. Ayurv. Pharm. Sci., 2, 1 (2011).

8. S. Manoharan, K. Kavitha, N. Senthil and G.L. Renju, Singapore Med. J., 47, 1038 (2006).

9. K.R. Chourasiya, K.P. Jain, K.S. Jain, S.S. Nayak and R.K. Agrawal, Pharmacol. Res., 1, 119 (2010).

10. R. Anitha and P. Kannan, Turk. J. Biol., 30, 139 (2006).

11. F. Anwar, A. Jamil, S. Iqbal and M.A. Sheikh, Grasas y Aceites, 57, 189 (2006)

12. B. Sultana, F. Anwar, M.R. Asi and S.A.S. Chatha, Grasas y Aceites, 59, 205 (2008).

13. J.B. Harborne and C.A. Williams, Phytochemistry, 55, 481 (1992).

14. A. Sofowora, J. Bioactive Agents, 21, 134 (1993).

15. A. Chaovanalikit and R.E. Wrolstad, J. Food Sci., 69, 67 (2004).

16. V. Dewanto, X. Wu, K.K. Adom and R.H. Liu, J. Agric. Food Chem., 50, 3010 (2002).

17. B. Tepe, Food Chem., 92, 89 (2005).

18. S. Iqbal, M.I. Bhanger and F. Anwar, Food Chem., 93, 265 (2005).

19. G.C. Yen, P.D. Duh and D.Y. Chuang, Food Chem., 70, 437 (2000).

20. D. Fireston, Official Methods and Recommended Practices of the American Oil Chemists Society (AOCS), Champaign, AOCS Press, Boulder Urbana IL, United States of America, edn. 5, pp. 1-150 (1997).

21. IUPAC, International Union of Pure and Applied Chemistry (IUPAC) Commission on Oils and Derivatives: Standard Methods for the Analysis of Oils, Fats and Derivatives, Revised C. Paquot and A. Hautfenne, 
Blackwell Scientific Publications, London, England, edn. 7, pp. 1-190 (1987).

22. M. Riaz, N. Rasool, I. Bukhari, M. Shahid, F. Zahoor, M. Gilani and M. Zubair, Afr. J. Microbiol. Res., 6, 5700 (2012).

23. P. Sharma and J.D. Sharma, J. Ethnopharmacol., 74, 239 (2001).

24. F. Anwar, M. Ali, A.I. Hussain and M. Shahid, Flavour Fragr. J., 24 170 (2009).

25. S.N. Hsu, S. Yonekura, Y. Lwai, T. Uemura, H.M. Robertson, C.H. Lee and A. Chiba, Drosophila Res. Conf., 47, 609 (2006).

26. F. Shahidi, in ed.: F. Shahidi, Measurement of Lipid Oxidation and Evaluation of Antioxidant Activity, In Natural Antioxidants, Chemistry, Health Effects and Applications, AOCS Press Champaign IL USA (1997).
27. F. Anwar, S.A.S. Chatha and A.I. Hussain, Grasas y Aceites, 58, 390 (2007).

28. L. Mcginely, Analysis and Quality Control for Processing and Processed Fats in Analysis of Oil Seeds, Fats and Fatty Foods, Elsevier Applied Science, New York, United Sates of America, edn 1, pp. 460-470 (1991).

29. F. Aslam, N. Rasool, M. Riaz, M. Zubair, K. Rizwan, M. Abbas, T.H. Bukhari and I.H. Bukhari, Int. J. Phytomed., 3, 567 (2011). 